\title{
COMMISSION 22: METEORS, METEORITES AND INTERPLANETARY DUST
}

\author{
(METEORES, METEORITES ET POUSSIERE INTERPLANETAIRE)
}

\author{
PRESIDENT: V. Porubčan \\ VICE-PRESIDENT: I. Mann \\ SECRETARY: W.J. Baggaley \\ ORGANIZING COMMITTEE: D. Asher, J. Borovička, M. Grady, \\ R.L. Hawkes, P. Jenniskens, P. Spurný, D.I. Steel, J. Watanabe, I.P. Williams \\ \& H. Yano
}

\section{Introduction}

Short reviews summarizing progress follow. The Commission has one representative in the inter-Division Working Group Near-Earth Objects (I.P. Williams) and one Working Group of its own Professional-Amateur Cooperation in Meteors consisting of P. Jenniskens (Chair), L. Bellot, H. Betlem, N. Bone, T. Cooper, M. Gijssens, G. Klar-Renner, V. Porubčan, J. Richardson, J. Watanabe, T. Yoshida and Jin Zhu. The activities of the WG were aimed to improve cooperation between professionals and amateurs in meteor research, to establish collaboration especially during the Leonid campaigns of November 1999-2001 facilitating participation of amateurs in NASA's Leonid Multi-Instrument Aicraft Campaigns and encouraging publication of amateur observations in the professional literature. The WG has established a www home page at http://www.phys.canterbury.ac.nz/iau22/proam and the IAU Commission $22 \mathrm{www}$ site is at http://www.phys.canterbury.ac.nz/iau22.

\section{Meetings}

Asteroids, Comets, Meteors 1999, Ithaca, USA, July 1999. IAU Coll. 181 Dust in the Solar System and other Planetary Systems, Canterbury, UK, April 2000. Leonid MAC Workhop 2000, Tel Aviv, Israel, April 2000. Catastrophic Events and Mass Extinctions: Impacts and Beyond, Vienna, Austria, July 2000. IAU JD 4 The Transneptunian Population, Aug. 2000. IAU JD 6 Applied Historical Astronomy, Aug. 2000. Meteoroids 2001, Kiruna, Sveden, August 2001. NATO Workshop Optics of Cosmic Dust, Bratislava, Slovakia, November 2001. AGU Fall Meeting, San Francisco, USA, December 2001. Leonid MAC Workshop 2002, Tokyo, Japan, May 2002. In addition there were in each year held the International Meteor Conferences (1999 Italy, 2000 Romania, 2001 Slovenia) organized by the International Meteor Organization and the annual meetings of the Meteoritical Society (1999 South Africa, 2000 USA, 2001 Italy).

\section{Photographic Meteors, Fireballs, Spectroscopy (P. Spurný and J. Borovička)}

The most interesting results from the European Photographic Fireball Network (EN) are described in Tóth, Kornoš, \& Porubčan (2000) and in Spurný \& Borovička (2001) and Spurný, Spalding \& Jacobs (2001). In the latter, the rare Aten-type orbit EN310800 Vimperk fireball, exceptional by its deep penetration in the atmosphere and heliocentric orbit with very short semimajor axis - only $0.80 \mathrm{AU}$ - is analysed using common photographic and radiometric observations giving very precise and detailed light-curves. Photographic data on very bright Leonids observed in China during the so called fireball night in 1998 are presented in Spurný et al. (2000a,b). Extreme beginning heights for bright Leonids up 
to $200 \mathrm{~km}$ altitude and diffuse structures with dimensions of the order of kilometers above $130 \mathrm{~km}$ (Spurný et al. 2000b).

Photographic meteors (Trigo et al. 1999, 2000; Langbroek \& ter Kuile 1999); Precise data from double-station Leonid observations in (Betlem et al. 1999, 2000) where precise orbits of Leonid meteors enabled to distinguish different dust components.

The fall, recovery, orbit and composition of a new type of carbonaceous chondrite - the Tagish Lake meteorite - is described in Brown et al. (2000) with detailed atmospheric flight in Brown et al. (2002). The interpretation of fireball physical characteristics is presented in Brown, ReVelle \& Hildebrand (2001). Basic orbital and atmospheric data on the May 6, 2000 Moravka meteorite fall are described in Borovička, Spurný \& Ceplecha (2001). Data on the trajectory and orbit of a superbolide over Greenland on December 9, 1997 are presented in Pedersen et al. (2001). The trajectory and orbit of the Tunguska event are discussed in Bronshten (1999). The theory of penetration of large meteoric bodies into the atmosphere is described in Nemchinov, Popova \& Teterev (1999).

Lightcurves of bright meteors are studied in Beech \& Brown (2000), Beech (2001), Zinn et al. (1999) and Spurný, Spalding \& Jacobs (2001) and luminosity of fainter meteors is analyzed in Jiang \& Hu (2001) and in Bellot Rubio et al. (2001, 2002). Fragmentation and densities of meteoroids are discussed in Zubareva, Stulov \& Stulov (1999), Stulov (2000), Stulov \& Titova (2001), ReVelle (2001c), Kuznetsov \& Novikov (2001), Artemieva \& Shuvalov (2001) and Babadzhanov (2002). A new model of the dynamic behavior of meteoroids from precise photographic records was developed by Ceplecha, Borovička \& Spurný (2000) and ReVelle \& Ceplecha (2001). Porosity of meteoroids is studied in ReVelle (2001d). Entry modeling of larger Leonid meteoroids and application to the Leonid bolide of Nov. 17, 1998 is presented in ReVelle (2001a,b). Formation of disturbed area around meteor body was studied by Popova et al. (2001) and ablation processes were studied by Pecina (2001). Rosaev (2001) searched parental bodies for fireballs and meteorites with well determined orbits. Long-term orbital studies of bright fireballs are presented in Foschini et al. (2000).

Photographic spectra were reported by Borisov et al. (2001) and Spurný \& Borovička (2001). New techniques of image intensified video and CCD were employed for the observations of Leonid meteor showers since 1998 and new spectral windows opened in the infrared and ultraviolet. Video spectra of relatively faint meteors were presented by Borovička, Stork \& Bocek (1999), Abe et al. (2000), Rairden, Jenniskens \& Laux (2000) and Borovička (2001) while Borovička \& Jenniskens (2000) obtained the video spectrum of a bright Leonid fireball and its afterglow. Spectral identification work by Murray et al. (2000) using $\mathrm{Na}$ and $\mathrm{Mg}$ and Rairden et al. (2000).

Jenniskens et al. (2000b) modeled atmospheric emissions in meteor spectra and the possible delivery of organic matter to the Earth while Rossano et al. (2000) detected the mid-IR (3-5.5 $\mu \mathrm{m})$. Almozino \& Topaz (2000) reported ground based detection of meteors in the UV (around $320 \mathrm{~nm}$ ). Recently, Jenniskens et al. presented first ever spaceborne meteor UV spectrum (251-384 nm). Emissions of $\mathrm{Mg}, \mathrm{Fe}, \mathrm{Si}$ and $\mathrm{OH}$ were detected. Theoretical investigations on meteor vapor temperatures and emission spectra were done by Boyd (2000) and Popova et al. (2000) while Rietmeier (2000) related such to the properties of interplanetary dust.

Clemesha et al. (2001) obtained multi-wavelength filtered images of a persistent train. Russel et al. (2000) obtained unique mid-infrared (3-13 $\mu \mathrm{m})$ spectra of persistent trains with a C-H feature controversially interpreted as a 'fingerprint' of mesospheric bacteria by Wickramasinghe \& Hoyle (2001).

\section{Radar Techniques (W.J. Baggaley and D. Janches)}

A detailed description of the technical differences between the use of transverse scatter and radial scatter large aperture (HPLA) radars is given by Pellinen-Wannberg (2001). Close et al. (2000) reported high polarization ratio measurements of meteor head echoes 
utilizing the Advance Research Projects Agency Long-Range Tracking and Instrumentation Radar (ALTAIR; Marshall Islands). The $430 \mathrm{MHz}$ Arecibo Observatory (AO) radar by Janches et al. (2000a) provided direct Doppler instantaneous meteor velocity measurements clearly associating the meteor head-echo with a region of plasma moving at the speed of the meteoroid.

Janches et al. (2000b) utilized AO via measurements of micrometeor decelerations to estimate micrometeoroid sizes and masses. Mathews et al. (2001) used these results to estimate the mass flux into the upper atmosphere for the mass range accessible to AO.

Hunt et al. (2001) and Close et al. (2002) performed similar studies using ALTAIR dual frequency (VHF/UHF) observations during the Leonids 1998 storm. Nishimura et al. (2001) reported high sensitivity radar-optical observations of faint meteors utilizing the Middle and Upper atmosphere radar in Japan and Janches et al. (2002) reported tristatic UHF meteor observations (EISCAT northern Scandinavia). Similar observations were also reported by Heinselman et al. (2001) (1290 MHz Sondrestrom radar, Greenland) and Ericksson et al. (2001) (440 MHz Haystack Observatory Massachusetts, USA) which detect a similar meteoroid mass range to ALTAIR.

The transverse scatter continuous operation facility AMOR with installation of an enhanced phase capability now produces an independent meteoroid speed measurement while directional switching has enabled a more complete surveillance of the celestial sphere (Baggaley, Marsh et al. 2001). Webster et al. (2001) describe a meteor radiant mapping system; a new technique of Fresnel holography for delineating small scale structure and fragmentation was presented by Elford (2001).

The meteor velocity distributions reported by Janches et al. (2001) seem to be dominated by a high speed component (peak $\sim 50 \mathrm{~km} / \mathrm{sec}$ ) Similar results were discussed by Sato et al. (2000) utilizing the MU radar and Brown et al. (2001) utilizing the ALTAIR system. High velocity distributions seem to be consistent in all HPLA observations (Sato 2000; Ericksson 2001; Hunt 2001; Janches 2001; Mathews 2001). A consistent result among HPLA radars is that they detect mostly the sporadic meteor background and are not sensitive to meteor showers (Sato 200; Brown 2001; Ericksson 2001; Janches 2001, 2002; Pellinen-Wannberg 2001).

Plasma instabilities of meteor trails have also been observed and studied. Zhou et al. (2001) reported field aligned irregularities using the MU radar. Oppenheim et al. (2000) presented simulations showing that meteor trails are Farley-Buneman gradient drift unstable, and that the instability leads to plasma turbulence. Dyrud et al. (2001) demonstrated that instability leads to an anomalous cross field diffusion that can be an order of magnitude larger than theory expected. Dyrud et al. (2002) showed that the delay between head echo and non-specular trails in the ALTAIR data resulted from the time scale for the establishment of plasma turbulence, and that meteor trails are unstable over a limited altitude range, as also clearly shown in observations of non-specular trails.

\section{Electro-Optical Observations (R.L. Hawkes and S. Molau)}

Hawkes et al. (2001) describe work and the use of inexpensive unintensified CCD meteor camera and digital recording techniques as do Brändström et al. (2001) and Jiang \& Hu (2001). Two software solutions which have been developed for automated detection and analysis of electro-optical meteor observations (MetRec by S. Molau and MeteorScan by P. Gural) are both in widespread use now and were key to the analysis of the large amount of data generated by the various Leonid campaigns. Jenniskens (2000) and Jenniskens et al. (2000) investigated a hybrid video-human observer method for meteor detection. Koschny $\&$ Sender (2000) compared results from ground and airborne instruments. The combination of powerful detectors and automated software has permitted the development of systems to provide early warning systems to satellite operators (e.g. Brown et al. 2000, Treu et al. 2000 , Zender et al. 2000). Video detectors and automated software are now being routinely used in fireball networks (e.g. Beech \& Illingworth 2001a,b), and occasionally serendipity 
surveillance video records can result in fireball orbits (e.g. Docobo \& Ceplecha 1999; Pedersen et al. 2001) or other scientifically important information (Murphy \& Sanders 2000). MeteorSim (Monte Carlo simulation based software developed by P. Gural) has provided a new tool to calibrate video meteor observations and determine meteoroid flux values (Gural \& Jenniskens 2000; Molau et al. 2002). For the first time meteor shower activity is monitored on a regular basis throughout the year using video technology and automated detection (Molau 2000, 2001; Nitschke 2001). Almoznino \& Topaz (2000) and Jenniskens et al. (2002b) used intensified CCD system sensitive in the ultraviolet to study Leonid meteors. High definition television spectroscopic results for the Leonids were reported by Abe et al. (2000). Kozak et al. (2001) studied spatial and photometric analysis algorithms for application to video meteor work.

Extensive campaigns on the Leonids include: 1998 Leonids - Borovička et al. (1999), Jenniskens (1999), Murray et al. (1999), Pawlowski (1999), Campbell et al. (2000), Bone \& Evans (2001); 1999 Leonids - Molau et al. (1999, 2001), Brown et al. (2000), Gural \& Jenniskens (2000), Jenniskens et al. (2000), Koschny \& Zender (2000), Murray et al. (2000), Rendtel et al. (2000), Singer et al. (2000), Campbell et al. (2001), Holman \& Jenniskens (2001), Molau (2001), Pawlowski et al. (2001), Brown et al. (2002a); 2000 Leonids - Campbell et al. (2001), Brown et al. (2002b); 2001 Leonids - Molau et al. (2002), Watanabe et al. (2002). Fine structure in the Leonid activity profiles was reported by (Singer et al. 2000).

Work on other showers include: Jenniskens et al. (2002a) and Jenniskens \& Lyttinen (2001) (2000 Ursid), Meng (2002) ( $\iota$-Aquarid), Arlt (2001) (dust tail of Comet 73/PSchwassmann-Wachmann 3), Triglav (2001) (Taurids), Fujiwara et al. (2001) (Giacobinids); Bendtel \& Gliba (2000) (Bootids).

The physical structure, grain size and mode of ablation of meteoroids have been studied by Murray et al. (1999, 2000), Koten \& Borovička (2001), Campbell et al. (2001), Fisher et al. (2000) and Hawkes et al. (2001). Jet-like ablation features on some fast high Leonid meteors were reported by LeBlanc et al. (2000), Spurný et al. (2000) and by Taylor et al. (2000). The physical mechanism responsible for this transverse spread is not yet completely understood. Koten et al. (2001) found that extreme beginning heights are not restricted to Leonid meteors. Hawkes et al. (2002) measured the grain size spread for several 1998 Leonids with intense flares. Jiang \& $\mathrm{Hu}$ (2001) found evidence for rapid fluctuations on the light curve indicative of a dustball model.

Pawlowski \& Hebert (2000) and Pawlowski et al. (2001) have used a long focal length $3 \mathrm{~m}$ diameter liquid mirror telescope coupled to a video rate intensified CCD to study very faint small-mass Leonid meteors and provide a technique for studying meteor ablation at high spatial resolution. Video rate CCD detectors have been used to study meteoroid impacts on the darkened lunar surface (Bellot Rubio et al. 2000a,b, Ortiz et al. 2002, Yanagisawa \& Kisaichi 2002, Artemeva et al. 2001).

\section{Bolide Dynamics, Fragmentation, Ablation, Differential Ablation, Lumi- nosity, Hypersonic Aerodynamics and Physical Structure (P. Brown and D. Revelle)}

Papers were presented on bolide rotation and associated luminosity changes by Beech (2001), Beech \& Brown (2000), Novikov \& Sokolov (2001); on fragmentation (ReVelle (2001d, 2002a); on ablation and on luminosity (ReVelle 2001a,b,d,e; ReVelle \& Ceplecha 2001a); on differential meteor atom ablation (von Zahn 2001); on mathematically inverting the observational data to infer meteor-fireball properties (Pecina, 2001; ReVelle \& Ceplecha 2001a); on inferring shape change characteristics of meteor fireballs from an analysis of very precise bolide cases (ReVelle \& Ceplecha 2001b); on hypersonic aerodynamic, equilibrium, chemically-reacting air temperature computations (Thames et al. 2000); on transitional to free molecule flow effects (Popova et al. 2001), on meteoroid explosions and on the general problems of meteor and bolide modeling (Kruchynenko, 2001); on Leonid entry 
modeling and its applications (ReVelle 2001a,b; Popova et al. 2001); on quasi-continuous fragmentation processes (Kuznetsov \& Novikov 2001); on a semi-empirical differential luminous efficiency parameter (ReVelle \& Ceplecha 2001a); on aerodynamic forces affecting fragments dispersion following break-up (Su 2001); on meteoroid bulk density determinations (ReVelle 2001e). Artemieva \& Shuvalov (2001) examined bolide fragmentation effects in general in a planetary atmosphere. The Beneosov and other bolides were also modeled as an application of their approach.

The influx rate was considered by ReVelle (2001c). Associated formal errors have also been calculated for each cumulative bolide source energy category using globally available infrasonic array data. A cumulative, yearly average event was found to be 13-15 kt in good agreement with other methods.

Pedersen et al. (2001) discussed the Greenland superbolide of Dec 7, 1999; the very weak and low bulk density carbonaceous chondrite, Tagish Lake (fifth meteorite orbit) was discussed by Brown et al. (2000), by Brown, ReVelle \& Hildebrand (2001), and by Brown et al. (2002).

Spurný \& Borovička (2001) present fall data for the recent Neuschwanstein meteorite fall (seventh meteorite orbit). The Neuschwanstein meteorite fall has an orbit identical to that of the first recovered and photographed meteorite, Příbram, and confirms the presence of meteorite streams in near-Earth space (along with the Innisfree-Ridgedale connection determined earlier with data from the Candian MORP network). Several recent cases now exist of bolides detected simultaneously using satellites (with both optical and infrared recordings in some cases), by video cameras, by conventional all sky and guided camera systems, by ground-based radiometers and by using infrasonic IMS (International Monitoring System) and other arrays in Europe. The Moravka meteorite fall (May 6, 2000) was recorded in greater detail than any meteorite-producing fireball in history as reported by Borovička et al. (2000) and ranks as the sixth meteorite whose orbit is precisely determined.

\section{Meteoroid Orbits (W.J. Baggaley and V. Porubčan)}

The IAU Meteor Data Center established for archiving, documentation and dissemination of information on meteor orbits at present catalogues 4581 precise photographic orbits, 1451 video orbits and 63330 radar determined orbits (Lindblad 2001). The MDC database of photographic orbits has gradually been updated (Lindblad et al. 2001), all the orbits were recomputed and verification of mutually dependent parameters has been performed. All the files with the pertinent documentation will be placed on a www-site to enable their free downloading.

The largest contribution to archived meteoroid orbits remains the meteor radar AMOR in New Zealand, with a limiting magnitude of about +14 , yielding up to $10^{3}$ orbits per day. Galligan \& Baggaley (2001) describe the solar system dust cloud orbit survey achieved with this continuously operating facility. The inflow directions of extra-solar meteoroids has been delineated (Baggaley 2000; Baggaley \& Galligan 2000) with identification of probable sources. Orbital distribution of interplanetary dust particles using the Arecibo Observatory (AO) radial geometry system has been reported by Janches et al. (2001). Meisel at al. (2002) reported a sample of AO detected events with hyperbolic orbits and inferred a supernova event as responsible. Baggaley \& Neslušan (2001) modelled the orbital characteristics of an inflow of extra-solar dust.

Precise photographic orbits of 47 Leonids obtained from multi-station observations in 1999 on expedition in Spain are presented by Betlem et al. (2000). The data show an unresolved compact cluster of radiant at a position identical with the Leonids from the outburst in 1998. DeLignie et al. (2000) based on double-station video observations of the Leonid shower of 1998 computed 55 trajectories and orbits of meteoroids in the visual magnitude range +0 to +6 with the data suggesting the presence of at least two merged dust components. 
Double-station video observations on Oct. 21-22, 1995 in the Netherlands, resulted in orbits for Orionids, S Taurids and Leo Minorids. For the Orionid radiant, new values for the radiant motion were derived and the width of the radiant is shown to increase for small particles (de Lignie \& Betlem 1999). From multi-station video observations on October 1998 Fujiwara et al. (2001) recorded 48 Giacobinid orbits. Ueda et al. (2001) from doublestation TV observations in 1998 and 1999 have determined 77 and 186 orbits in 1998 and 1999, respectively. Among them there are 224 sporadic meteors and of the stream meteors the most numerous are Leonids (22) and N Taurids (13). Stork (2001) reports parameters for 207 non-stream and stream meteors. Bright bolides orbits are reported in the section on Bolides (see above).

\section{Meteor Showers (P. Jenniskens and D.J. Asher)}

Jenniskens \& Butow (1999), Jenniskens et al. (2000a), Asher (2000) and Jenniskens (2001 $\mathrm{a}, \mathrm{b})$ give reviews of Leonid outbursts. Special issues on Leonid storm research appeared in Meteoritics \& Planetary Science $(34,1999)$, Earth, Moon \& Planets (82-83, 2000), J. Geophys. Res. Lett $(27,2000)$, Meteoroids (ESA SP-495, 2001), and ISAS SP-16 (2002).

The first detailed working prediction models for young meteor showers have evolved with the work of McNaught \& Asher (1999a) and Lyytinen (1999). Kondrat'eva et al. (2000) continued their pioneering techniques on outburst modeling. Kozai (2002) demonstrated how these results can be derived semi-analytically. New observations led to a better understanding of the dust distribution in the trails after ejection (Asher \& McNaught 2000). Lyytinen \& Van Flandern (2000) discussed the possible effects of radiation pressure on the grains. Jenniskens et al. (2000c) introduced the Lorentz profile for dust distribution in Earth's path. Jenniskens \& Gustafson (2000) and Jenniskens (2001c,d) found an exponential distribution in a radial direction to the Sun and small discrepancies in calculated trail positions. McNaught \& Asher (2001) investigated radiant structure. Arlt \& Brown (1999), Betlem \& van Mil (1999), Bus (1999b, 2000), deLignie et al. (2000), and Uchiyama (2002) discussed the separation of different trail components. Lyytinen et al. (2002) studied the effects of radiation. Müller et al. (2001), Imponente \& Sigismondi (2001), and Ma \& Williams (2001) discuss the general relationships between ejection and place in the dust trail. Epifani et al. (2001) and Reach et al. (2000) present models for the 2P/Encke and 103P/Hartley 2 dust trails. Planetary perturbations and dust ejection processes are covered in (Brown \& Arlt 2000; Brown \& Cooke 2001; Cooke 2001; Göckel \& Jehn 2000; Wu 1999).

The Leonids were observed from space (Jenniskens et al. 2000b), from air in the international Leonid Multi-Instrument Aircraft Campaign (Jenniskens \& Butow 1999; Jenniskens et al. 2000a) and from the ground (Betlem 1999; Betlem et al. 2000; Brown et al. 2000; Campbell et al. 2001; Brosch et al. 2001; Babina et al. 2000; Cevolani et al. 2000; McBeath (2000); Wu \& Zhang 2000; Ogawa \& Uchiyama 2001; Simek \& Pecina 2001; Singer et al. 2001; Trigo-Rodriguez et al. 2001a,b; Ueda \& Maegawa 2001; Watanabe et al. 2000, 2002; Wu 2001 and Wu et al. 2001).

McNaught (1999) and McNaught \& Asher (1999b) discussed aspects of the observing conditions. A theme of many campaigns was providing rapid information on shower activity, including near-real time flux measurements for satellite operators (Treu et al. 2000). Global visual observations are summarized in Arlt \& Brown (1999), Arlt et al. (1999), Arlt \& Gyssens (2000), and Arlt et al. (2001). Absolute calibration of flux measurements is discussed by Holman \& Jenniskens (2001), Belkovich et al. (2000), Jenniskens (1999b), Brown et al. (2000), Koschny \& Zender (2000), Campbell et al. (2001) and Gural (2001). A review on the satellite impact hazard of meteor showers is given by Jenniskens (1999a), McBride \& McDonnell (1999), McBride et al. (1999), Drolshagen (2001), Ekstrand \& Drolshagen (2001), Graham et al. (2001), and Schwanethal \& McBride (2001).

Murray et al. (1999, 2000), Campbell et al. (2000), Koten \& Borovička (2001) and Jiang \& Hu (2001) discuss grain morphology in different dust trail encounters. The issue of fragmentation in the meteor shower has been investigated by Gural \& Jenniskens (2000), Singer et al. (2000), Molau et al. (2001) and Karpov (2001). Perseid shower clustering was 
studied by Svoren̆ et al. (2001). Jenniskens (2001a) identifies fragmentation in the comet coma as a possible cause of the Lorentz profile wings of dust trails.

The smallest meteoroid grains in the dust trail are responsible for the scattered light from Leonid debris in space (Nakamura et al. 2000). Ground-based observations of faint Leonid meteoroids are discussed by $\mathrm{Ma}$ et al. (2001). Jenniskens \& Betlem (2000) discuss the formation of the Leonid filament component. Detections at ELF/VLF of faint Leonid meteors are reported by Price \& Blum (2000).

The biggest meteoroids in the stream (Toth et al. 2000) may contribute to the extended Moon's sodium atmosphere, which was detected during the Leonids in 1998 (Smith et al. 1999, Wilson et al. 1999). Moon impacts were first seen in 1999 (Bellot-Rubio et al. 2000a,b; Ortiz et al. 2000; Dunham et al. 2000; Sigismondi \& Imponente 2000a,b; and Khavroshkin \& Tsyplakov 2001).

Following the Leonids, similar methods successfully predicted the 2000 Ursid outbursts confirming the importance of resonances (Jenniskens \& Lyytinen 2000, 2001a; Jenniskens 2000a,b; deLignie \& Johannink 2001; Jenniskens et al. 2002). Asher \& Emel'yanenko (2002) applied the techniques to the 1998 June Bootid outburst (Arlt et al. 1999). Luethen et al. (2001) made an (unconfirmed Arlt 2001) prediction for trails of Comet 73P/SchwassmannWachmann 3. Jenniskens \& Lyytinen (2001b) discuss the case for C/2000 WM1 (LINEAR), for the first time describing the one-revolution trail of a long-period comet. Dynamical work on outbursts was done by Arter \& Williams (2002) and Tanigawa \& Hashimoto (2000).

Arlt (2000) and Rendtel (2002) discuss the June Bootids in years after the 1998 outburst. Fujiwara et al. (2001) described TV observations of 1998 Giacobinids, while Bus (1999a) presents radio observations. Arlt \& Handel (2000) detected no new peak in 2000 Perseids. The Perseids' long term activity was studied by Lindblad (2000). The Lyrid annual shower activity curve was measured by Dubietis \& Arlt (2001). Features of various minor showers were determined from data analyses by Dubietis (2001), Dubietis \& Arlt (2002), Kidger (2000), Meng (2002) and Olech \& Wisniewski (2002).

Ryabova $(1999,2001)$ discusses the age of the Geminid stream, and calculations of showers due to other parent bodies were published by Babadzhanov (2001), Hasegawa (2001), Neslušan (1999) and Ryabova (2002).

\section{Aeronomy (W.J. Baggaley and E. Murad)}

Work on the Leonid meteor storm circumstances (Asher 1999; Asher et al. 1999a,b; Brown 1999; Rao 1999, 2000) accompanied campaigns to observe the expected storms (Jenniskens 2001; Jenniskens \& Butow 1999; Wu \& Zhang 2002).

An important component of the aeronomy aspects has been the attempt to develop a full meteor model that begins with a source function of meteor flux, ablation, and interaction of meteoroids with the atmosphere, resulting in the generation of trails and in the population of the equilibrium metal (ions and neutrals) layer in the D- and E-regions of the ionosphere. A modeling effort that combined a chemical scheme with a global transport model (Carter \& Forbes 1999) was limited to meteoric Fe and used an empirical metal source function was successful in predicting altitude and latitude variations.

The called differential ablation model of McNeil et al. (1998) has been successful in reproducing the abundances of metal ions in the normal D- and E-regions, and, more importantly, in explaining the observed abundances of metals in lidar observations of meteor trails (Höffner et al. 1999; von Zahn et al. 1999).

This model (which ignored thermal conductivity) is applicable to meteoroids that are relatively small. Other efforts at modeling have assumed that the meteoroids reheated to high temperatures so quickly that flash evaporation occurs before thermal equilibrium is established (Helmer et al. 1998; Kruschwitz et al. 2001; Plane et al., 1998, 1999a). This type of model has also been quite successful in explaining trail observations using lidar techniques (Eska et al. 1999; Gerding et al. 2000; Plane et al. 1999b). An attempt has been made to include effects of the aurora on the meteor metal abundances in polar 
region (Heinselman 2000). The formation of thin (1-2 km) sudden meteor atom layers (first reported for sodium by von Zahn et al. 1987 and reviewed by Plane \& Helmer 1994) have been expained by Cox \& Plane (1998) as the formation of $\mathrm{Na}^{+}$cluster ions that switch with $O$ atoms, eventually being neutralized in a descending sporadic $E$ layer.

Modeling the vaporization and heating of meteoroids as they enter the Earth's atmosphere has used Monte Carlo techniques (Boyd 2000; Popova et al. 2000). The former considered evaporation from large non-fragmenting meteoroids with particular application to the Leonids. This simulation found that the vaporized material forms a gaseous envelop that shields the meteoroid surface from direct impact by atmospheric gases. In the second study (Boyd 2000) similar results were obtained for a Leonid meteoroid. The geomagnetic control of meteor train diffusion has been compared with observations by Elford \& Elford (2001).

Because of interest in the Leonid storms of 1998-2001, several observations were made of the phenomenon of enduring and hollow trains (Chu et al. 2000; Clemesha et al. 2001; Grime et al. 2000; Jenniskens et al., 2000a,b,c; Jenniskens \& Rairden 2000; Kelley et al. 2000, 2002; Kruschwitz et al. 2001; Drummond et al. 2001a,b; Russell et al. 2000; Zinn et al. 1999). Most of the observations related to the larger meteoroids representative of the Leonids and it is likely that shock formation has to be taken into account for the explanation of the observations. Most of the observations report an orange glow and, where spectral information is available, $\mathrm{Na}$ is reported. The data reported by Zinn et al. (1999) were obtained for two persistent trails that exhibit the phenomenon of a hollow tube explained as arising from the depletion of ozone by its flash photolysis within the tube - only Na exposed to the atmosphere at the periphery of the trail can undergo chemiluminescent reactions that give rise to $\mathrm{Na}(\mathrm{D})$. The data presented by Chu et al. (2000) and Kelley et al. (2000) confirm the presence of $\mathrm{Na}$; the former also report the presence of $\mathrm{OH}$ chemiluminescence in the trail. Jenniskens et al. (2000a) present a spectrum that suggests that $\mathrm{FeO}$ is one of the emitters. Murad (2001) suggests that $\mathrm{FeO}, \mathrm{SO}$, and $\mathrm{SO}_{2}$ may all contribute to the chemiluminescence. Clearly high resolution spectra similar to those obtained by Borovička \& Jenniskens (2000), who reported emission lines due to a large number of metals, will have to be obtained before proper analysis of the phenomenon can be made.

V. Porubčan

President of the Commission

\section{References}

Note: articles with more than 3 authors have been reduced to et al. References to Proceedings of the Meteoroids 2001 Conference, Kiruna Sweden August 2001, ed. B. Warmbein (ESA SP-495, November 2001) have been reduced to SP-495. Radiant the Journal of the Dutch Meteor Society is reduced to Radiant.

Abe, S., Yano, H., Ebizuka, N. et al. 2000, Earth, Moon and Planets 82-83, 369

Almozino, E., \& Topaz, J.M. 2000, Earth, Moon and Planets 82-83, 391

Arlt, R., \& Brown, P. 1999, WGN, 27, 267

Arlt, R., Bellot-Rubio, L., Brown, P., \& Gyssens, M. 1999, WGN, 27, 286

Arlt, R. 2000, WGN, 28, 98

Arlt, R., \& Gyssens, M. 2000, WGN, 28, 195

Arlt, R., \& Handel, I. 2000, WGN, 28, 166

Arlt, R. 2001, WGN, 29, 93

Arlt, R., Rendtel, J., Brown, P., et al. 1999, MNRAS, 308, 887

Arlt, R., Kac, J., Frumov, V., Buchmann, A., \& Verbert, J. 2001, WGN, 29, 187

Artemieva, N.A. \& Shuvalov, V.V. 2001, J. Geophys. Res. 106, 3297

Artemeva, N.A. et al. 2001, Sol. Sys. Res., 35, 177 
Arter, T.R., \& Williams, I.P. 2002, MNRAS, 329, 175

Asher, D.J. 2000, in Proc. Int. Meteor Conf., ed. R. Arlt (Int. Meteor Org.), 5

Asher, D.J., \& Emel'yanenko, V.V. 2002, MNRAS, 331, 126

Asher D.J., 1999, MNRAS 307, 919

Asher D.J., Bailey M.E., \& Emel'yanenko V. V., 1999b, Irish Astr. J. 26, 91, 1999a.

Asher, D.J., Bailey M.E., \& Emel'yanenko V. V., 1999b, MNRAS 304, L53

Asher, D.J., \& McNaught, R.H. 2000, WGN, 28, 138

Babadzhanov, P.B. 2001, A\&A, 373, 329

Babadzhanov, P. B. 2002, Astron. Astrophys. 384, 317

Babina, J., Karkach, D., \& Kychyzhyeva, M. 2000, WGN, 28, 211

Baggaley W.J. 2000. J. Geophys.Res. (Space Phys.)105, 353.

Baggaley W.J. and Galligan D.P. 2001 SP-495, 663.

Baggaley W.J., Marsh S.H. et al., 2001, SP-495, 387.

Baggaley W.J. and Neslusan 2002, A \& A 382, 1118.

Beech, M. \& Brown, P. 2000, Planetary and Space Scince 48, 925

Beech, M. 2001, Mon. Not. R. Atron. Soc. 326, 937

Beech, M.\& Nikolova, S. 1999, Meteorit. Planet. Sci., 34, 849

Beech, M.\& Illingworth, A. 2001a, WGN J. Int. Met. Org., 29, 181

Beech, M.\& Illingworth, A. 2001b, WGN J. Int. Met. Org., 29, 200

Belkovich, O.I., Ishmukhametova, M.G., \& Suleymanov, SP-495, 91

Bellot Rubio, L. R. et al. 2001, SP-495, 525

Bellot Rubio, L. R. et al. 2002, Astron. Astrophys. 389, 680

Bellot Rubio, L.R., Ortiz, J.L., \& Sada, P.V. 2000a, Earth, Moon \& Planets, 82-83, 575

Bellot Rubio, L.R., Ortiz, J.L., \& Sada, P.V. 2000b, ApJ, 542, L65

Benitez Sanchez, O. 2001, WGN J. Int. Met. Org., 29, 37

Betlem, H. 1999, Radiant, 21, 1 (In Dutch)

Betlem, H., Jenniskens, P. et al. 1999, Meteoritics Planet. Sci. 34, 979

Betlem, H., Jenniskens, P., Spurný, P. et al. 2000, Earth, Moon and Planets 82-83, 277

Betlem, H., \& van Mil, O. 1999, Radiant, 21, 65

Bone, N.M.\& Evans, S.J. 2001, JBAA, 111, 333

Borisov, G., Bonev, T., \& Tsvetkov, M. 2001, Proceedings Int. Meteor Conf. 2000, p.27

Borovička, J. 2001, SP-495 203

Borovička, J. \& Jenniskens, P. 2000, Earth, Moon and Planets 82-83, 399

Borovička, J., Spurný, P. \& Ceplecha, Z., 2001, Meteoritics Planet. Sci. 36, A25

Borovička, J., Stork, R., \& Bocek, J. 1999, Meteorit. Planet. Sci., 34, 987

Boyd I.D., 2000, Earth, Moon, Planets 82-3, 93

Brändström et al. 2001, SP-495, 331

Bronshten, V.A. 1999, Meteoritics Planet. Sci. 34, A137

Brosch, N., Schijvarg, L.S., Podolak, M. et al. 2001, SP-495, 165

Brown P., 1999, Icarus 138, 287

Brown, P., \& Arlt, R. 2000, MNRAS, 319, 419

Brown, P., \& Cooke, B. 2001, MNRAS, 326, L19

Brown, P.G., Hildebrand, A.R., Zolensky, M.E. et al. 2000, Science. 290, 320

Brown, P.G., ReVelle, D.O., \& Hildebrand, A.R. 2001, SP-495, 497

Brown, P.G., ReVelle, D. O., et al. 2002, Meteoritics Planet. Sci. 37, 661

Brown, P. et al. 2000, Earth Moon Planets, 82-83, 149 
Brown, P., et al. 2000, Earth, Moon \& Planets, 82-83, 167

Brown et al., 2001, SP-495 469.

Brown, P. et al. 2002a, Planet. Space Sci., 50, 45

Brown, P. et al. 2002b, MNRAS, 335, 473

Bus, E.P. 1999a, Radiant, 21, 74

Bus, E.P. 1999b, Radiant, 21, 117

Bus, E.P. 2000, Radiant, 23, 65

Campbell, M.D., et al. 2000, Meteorit. Planet. Sci., 35, 1259

Campbell, M., Theijsmeijer, C., Jones, J. et al. 2001, SP-495 197

Carter L.N. \& Forbes J.M., 1999, Ann. Geophysicae 17, 190

Ceplecha, Z., Borovička, J. et al. 2000, Astron. Astrophys. 357, 1115

Cevolani, G., Pupillo, G., Porubčan, V. 2000, Earth, Moon \& Planets, 82-83, 265

Chu, X. et al. 2000, Geophys. Res. Let., 27, 1815

Clemesha, B.R., de Medeiros, A.F., Gobbi, D. et al. 2001, Geophys. Res. Let. 28, 2779

Close et al,, 2002, Radio Sci., 37, 1.

Close, S., Hunt, S.M., Minardi, M.J., et al. 2000, Radio Sci., 25, 1233

Cooke, B. 2001, Marshall Space Flight Center internal publication, 5 pp.

Cox R.M. \& Plane J. M. C., 1998, JGR 103, 6349

deLignie, M. \& Betlem, H. 1999, WGN J. Int. Met. Org., 27, 195

deLignie, M., Betlem, H., 1999, WGN 27-3/4, 195

deLignie, M., \& Johannink, C. 2001, Radiant 23:4, 71

deLignie, M.C., Langbroek, M., \& Betlem, H. 2000, Earth, Moon \& Planets, 82-83, 295

Docobo, J.A. \& Ceplecha, Z. 1999, A\&AS, 138, 1

Drolshagen, G. 2001, SP-495 533

Drummond, J.D. et al. 2001a, SP-495, 215

Drummond, J.D. et al. 2001b, J. Geophys. Res., 106, 21517

Dubietis, A. 2001, WGN, 29, 29

Dubietis, A., \& Arlt, R. 2001, WGN, 29, 119

Dubietis, A., \& Arlt, R. 2002, WGN, 30, 22

Dunham, D.W., et al. 2000, Lunar Planet Sci., XXXI, CD ROM

Dyrud L.P., Oppenheim M.M., \& vomEndt A.F., 2001, GRL 28, 2775

Dyrud et al., 2001, Geophys. Res. Let., In Press.

Ekstrand, V., \& Drolshagen, G. 2001, SP-495, 543

Elford W.G. 2001, SP-495, 405.

Elford W.G and Elford M.T., 2001, SP-495, 357

Epifani, E., Colangeli, L., Fulle, M., et al. 2001, Icarus, 149, 339

Ericksson et al., 2001, SP-495, 457.

Eska V., von Zahn U., \& Plane J.M.C., 1999, JGR 104, 17173

Fisher, A.A. et al. 2000, Planet. Space Sci., 48, 911

Foschini, L., Farinella, P. et al. 2000, A \& A 353, 797

Fujiwara, Y., Ueda, M., Sugimoto, M., et al. 2001, SP-495 123

Galligan D.P. and Baggaley W.J. 2001, SP-495, 569.

Gerding M., Alpers M.,von Zahn U., et al. 2000, JGR 105, 27,131

Göckel, C., \& Jehn, R. 2000, MNRAS, 317, L1

Graham, G.A., Kearsley, A.T., Drolshagen, G. et al. 2001, Adv. Space Res. 28, 1341

Grime B.W., Kane T.J., Liu A.Z., et al. 2000, GRL 27, 1819 
Gural, P. 2001, WGN, 29, 134

Gural, P., \& Jenniskens, P. 2000, Earth, Moon \& Planets, 82-83, 221

Hasegawa, I. 2001, SP-495, 55

Hawkes, R.L. et al. 2001, SP-495, 281

Hawkes, R.L. et al., 2002 COSPAR Colloq. Ser. (Pergamon), 15, 23

Heinselman C.J., 2000, JGR 105, 12,181

Helmer M., Plane J.M.C., Qian J., et al. 1998, JGR 103, 10,913

Höffner J., von Zahn U., McNeil W.J., et al. 1999, JGR 104, 2633

Holman, D., \& Jenniskens, P. 2001, WGN, 29, 77

Hunt et al., 2001, Meteoroids 2001, 451.

Imponente, G., \& Sigismondi, C. 2001, WGN, 29, 176

Janches et al., 2001, Icarus, 150, 206.

Janches et al., 2002, J. Geophys. Res., In Press.

Janches, D.J., Mathews, J.D., Meisel, D.D., et al. 2000a, Icarus, 143, 347

Janches, D., Mathews, J.D., Meisel, D., et al. 2000b, Icarus, 145, 53

Janches, D., Mathews, J.D., Meisel, D., et al. 2001, Icarus, 150, 206

Jenniskens, P. 1999a, Planet. Space Sci., 23, 137

Jenniskens, P. 1999b, Meteorit. Planet. Sci., 34, 959

Jenniskens, P. 2000, WGN J. Int. Met. Org., 28, 58

Jenniskens, P. 2000a, IAUC 7544, ed. D.W.E. Green (IAU MPC), 2000 December 18 Jenniskens, P. 2000b, IAUC 7548, ed. D.W.E. Green (IAU MPC) 2000 December 23 Jenniskens, P. 2001a, in Interplanetary Dust, ed. E. Gruen et al. Springer Verlag), p. 233 Jenniskens, P. 2001b, Mercury, 30, 14.

Jenniskens, P. 2001c, WGN, 29, 165

Jenniskens, P. 2001d, SP-495, 83

Jenniskens, P., \& Betlem, H. 2000, ApJ, 531, 1161

Jenniskens, P., \& Butow, S.J. 1999, Meteorit. Planet. Sci., 34, 933

Jenniskens, P., Butow, S.J., \& Fonda, M. 2000a, Earth, Moon \& Planets, 82-83, 1

Jenniskens, P., Crawford, C., Butow, et al. 2000c, Earth, Moon \& Planets, 82-83, 191

Jenniskens, P., \& Gustafson, B.A.S. 2000, WGN, 28, 209

Jenniskens, P., Lacey, M., Allan, B.J. et al. 2000a, Earth, Moon and Planets 82-83, 429

Jenniskens, P., \& Lyytinen, E. 2000, WGN, 28, 221

Jenniskens, P., \& Lyytinen, E. 2001a, WGN, 29, 41

Jenniskens, P., \& Lyytinen, E. 2001b, WGN, 29, 35

Jenniskens, P., Nugent, D., Tedesco, E., et al., 2000b, Earth, Moon \& Planets, 82-83, 305

Jenniskens P., Nugent D., \& Plane J. M. C., 2000b, Earth Moon Planets, 82-83, 471

Jenniskens P., \& Rairden R. L., 2000, Earth Moon Planets, 82-83, 457

Jenniskens, P., Tedesco, E., Murthy, J. et al. 2002, Meteoritics Planet. Sci. 37, 1071

Jenniskens, P. Wilson, M.A., Packan D. et al. 2000b, Earth, Moon and Planets 82-83, 57

Jenniskens, P. et al. 2002a, Icarus, 159, 197

Jenniskens, P., et al. 2002, Icarus, in press

Jiang, X. \& Hu, J. 2001, Planetary and Space Science 49, 1281

Kane T. J., 2002, JGR in press

Karpov, A. 2001, SP-495, 27

Khavroshkin, O.B., \& Tsyplakov, V.V. 2001, SP-495, 13

Kelley M.C., Gardner C.S. , Drummond J., et al. 2000, GRL 27, 1811 
Kelley M.C., Kruschwitz C.A., Gardner C. S., et al. 2002, J.Geophys. Res. in press.

Kidger, M.R. 2000, WGN, 28, 171

Kondrat'eva, E.D., Murav'eva, et al. 2000, Solar System Res., 34, 237

Koschny, D., \& Zender, J. 2000, Earth, Moon \& Planets, 82-83, 209

Koten, P., \& Borovička, J. 2001, SP-495, 259

Koten, P. et al. 2001, SP-495, 119

Kozai, Y. 2002, Proc. Jap. Acad., 78(B), 84

Kozak, P., Rozhilo, A.A., \& Taranukha, Y.G. 2001, SP-495, 337

Kruchynenko, V.G. 2001, SP-495, 351

Kruschwitz, C.A., Kelley, M.C., Gardner, C.S. et al. 2001, J. Geophys. Res. 106, 21525

Kuznetsov, V.L. \& Novikov G.G. 2001, in Meteoroids 2001, p. 255

Langbroek, M. \& ter Kuile, C. 1999, Radiant 21, 128

LeBlanc, A.D. et al. 2000, MNRAS, 313, L9

Lindblad, B.A., 2001, SP-495, 71

Lindblad, B.A., Neslušan, L. et al. 2001, SP-495, 73

Lindblad, B.A. 2000, Planet. Space Sci., 48, 905

Luethen, H., Arlt, R., \& Jager, M. 2001, WGN, 29, 15

Lyytinen, E. 1999, Meta Res. Bull., 8, 33

Lyytinen, E.J., \& van Flandern, T. 2000, Earth, Moon \& Planets, 82-83, 149

Lyytinen, E., Nissinen, M., \& van Flandern, T. 2001, WGN, 29, 110

Ma, Y.H., He, Y.W., \& Williams, I.P. 2001, MNRAS, 325, 457

Ma, Y.H., \& Williams, I.P. 2001, MNRAS, 325, 379

Mathews, J.D., Janchez, D., Meisel, D., et al. 2001, Geophys. Res. Lett., 28, 1929

McBeath, A. 2000, WGN, 28, 69

McBride, N., Green, S.F., \& McDonnell, J.A.M. 1999, Adv. Space Res., 23, 73

McBride, N., \& McDonnell, J.A.M. 1999, Planet. Space Sci., 47, 1005

McNaught, R.H. 1999, WGN, 27, 164

McNaught, R.H., \& Asher, D.J. 1999a, WGN, 27, 85

McNaught, R.H., \& Asher, D.J. 1999b, Meteorit. Planet. Sci., 34, 975

McNaught, R.H., \& Asher, D.J. 2001, WGN, 29, 156

McNeil W.J., Lai S. T., \& Murad E., 1998, JGR, 103, 10899

Meisel et al., 2002, ApJ, 567, 323.

Meng, H. 2002, WGN, 30, 32

Molau, S. 2000, Proc. Inter. Meteor Conf. 2000, 31

Molau, S. 2001a, Proc. Inter. Meteor Conf. 2001, 55

Molau, A. 2001b, SP-495, 315

Molau, S., Gural, P.S., \& Okamura, O. 2002, WGN J. Int. Met. Org., 30, 3

Molau, S., Rendtel, J., \& Bellot-Rubio, L.R. 2001, Earth, Moon \& Planets, 87, 1

Molau, S., Rendtel, J., \& Nitschke, M. 1999, WGN J. Int. Met. Org., 27, 296

Müller, M., Green, S.P., \& McBride, N. 2001, SP-495, 47

Murad, E. 2001, Meteoritics Planet. Sci. 36, 1217

Murray, I.S., Beech, M., Taylor, M.J. et al. 2000, Earth, Moon and Planets 82-83, 351

Murray, I.S., Hawkes, R.L., \& Jenniskens, P. 1999, Meteorit. Planet. Sci., 34, 949

Murphy, J.A.\& Sanders, F.H. 2000, Meteorit. Planet. Sci. (Supp.), A115, 35, 115

Nakamura, R., Fujii, Y., Ishiguro, M., et al. 2000, ApJ, 540, 1172

Nemchinov, I.V., Popova, O.P. \& Teterev A.V. 1999, J. Eng. Phys. Thermophys. 72, 1194 
Neslusan, L. 1999, A\&A, 351, 752

Nishimura et al., 2001, IEICE Trans. Commun., 12.

Nitschke, M. 2001, Proc. Inter. Meteor Conf. 2001, 68

Novikov, G.G. and O.V. Sokolov. 2001, SP-495, 287.

Ofek, E. 1999, WGN J. Int. Met. Org., 27, 172

Ogawa, H., \& Uchiyama, S. 2001, WGN, 29, 206

Olech, A., \& Wisniewski, M. 2002, A\&A, 384, 711

Oppenheim M.M., vomEndt A. F., \& Dyrud L. P., 2000, GRL 27, 3173

Ortiz, J.L. et al. 2002, ApJ, 576, 567

Ortiz, J.L., Sada, P.V., Bellot Rubio, L.R., et al. 2000, Nature, 405, 921

Pawlowski, J.F. 1999, Meteorit. Planet. Sci., 34, 945

Pawlowski, J.F., \& Hebert, T.T. 2000, Earth, Moon \& Planets, 82-83, 249

Pecina, P. 2001, SP-495, 271

Pedersen, H., Spalding, R.E., et al. 2001, Meteoritics Planet. Sci. 36, 549

Pellinen-Wannberg, A., 2001, SP-495,443.

Plane J. M. C., Cox R. M., Qian J., et al. 1998, JGR 103, 6381

Plane J. M. C., Cox R. M., \& Rollason R. J., 1999a, Adv. Sp. Res. 24, 1559

Plane J. M. C., Gardner C. S., Yu J. R., et al. 1999b, JGR 104, 3773

Plane J. M. C., \& Helmer M., 1994, in Research in Chemical Kinetics, Elsevier.

Popova, O.P., Sidneva S.N., Shuvalov V.V. et al. 2000, Earth, Moon and Planets 82-83, 109

Popova, O.P., Sidneva, S.N. et al. 2001, SP-495, 237

Price, C., \& Blum, M. 2000, Earth, Moon \& Planets, 82-83, 545

Rairden, R.L., Jenniskens, P., \& Laux, C.O. 2000, Earth, Moon and Planets 82-83, 71

Rao J., 1999, WGN 27, 177

Rao J., 2000, Sky \& Telescope, 99, 31

Reach, W.T., Sykes, M.V., Lien, D., et al. 2000, Icarus, 148, 80

Rendtel, J. 2002, WGN, 30, 85

Rendtel, J. \& Gliba, G. W. 2000, WGN J. Int. Met. Org., 28, 13

Rendtel, J. et al. 2000, WGN J. Int. Met. Org., 28, 150

ReVelle, D.O. 2001c, SP-495, 483.

ReVelle, D.O. 2001a, SP-495, 149

ReVelle, D.O. 2001b, SP-495, 179

ReVelle, D.O. 2001c, SP-495, 491

ReVelle, D.O. 2001d, SP-495, 513

ReVelle, D.O. \& Ceplecha, Z. 2001 SP-495, 507

Rietmeijer, F.J.M. 2000, Meteoritics Planet. Sci. 35, 1025

Rosaev, A.E. 2001, SP-495, 477

Rossano, G.S., Russell, R.W., Lynch, D.K. et al. 2000, Earth, Moon and Planets 82-83, 81

Russel, R.W., Rossano G.S., Chatelain M.A. et al. 2000, Earth, Moon \& Planets 82-83, 439

Ryabova, G.O. 1999, Solar System Res., 33, 258

Ryabova, G.O. 2001, SP-495, 77

Ryabova, G.O. 2002, Solar System Res., 36, 234

Sato et al., EICE Trans. Commun., E83-B, 1990.

Schwanethal, J.P., \& McBride, N. 2001, Adv. Space Res., 28, 1335

Sigismondi, C., \& Imponente, G. 2000a, WGN, 28, 54

Sigismondi, C., \& Imponente, G. 2000b, WGN, 28, 230 
Simek, M., \& Pecina, P. 2001, A\&A, 365, 622

Singer, W., Molau, S., Rendtel, et al. 2000, MNRAS, 318, L25

Singer, W., Mitchell, N.J., \& Weiss, J. 2001, SP-495, 221

Smith, S.M., Wilson, J.K., Baumbardner, J., et al. 1999. Geophys. Res. Lett., 26, 1649

Spurný, P., Betlem, H., Leven, J. et al. 2000a, Meteoritics Planet. Sci. 35, 243

Spurný, P., Betlem, H., Jobse, K. et al. 2000b, Meteoritics Planet. Sci. 35, 1109

Spurný, P., Spalding, R.E. \& Jacobs, C. 2001, SP-495, 2001, 135

Spurný, P. \& Borovička, J. 2001, SP-495, 519

Stulov, V.P. 2000, Solar Syst. Res. 34, 235

Stork, R. 2001, SP-495, 319

Stulov, V.P. \& Titova, L. Yu. 2001, Solar Syst. Res. 35, 315

$\mathrm{Su}$, Y. 2001, SP-495 Meteoroids 2001, 345.

Svoren, J., Porubčan, V., \& Neslusan, L. 2001, SP-495, 105

Tanigawa, T, \& Hashimoto, T. 2000, Earth, Moon \& Planets, 88, 27

Taylor, M.J. et al. 2000, Earth Moon Planets, 82-83, 379

Thames, C.D. et al. 2000, J. Thermophysics (Tech. Notes), 15, 127

Tóth, J., Kornoš, L., \& Porubčan V. 2000, Earth, Moon \& Planets 82-83, 285

Trayner, C., Bailey, N. J., \& Haynes, B. R. 2000, Proc. Inter. Meteor Conf. 2000, 38

Treu, M.H., Worden, S.P, et al., 2000, Earth, Moon \& Planets, 82-83, 27

Triglav, M. 2001, Proc. Inter. Meteor Conf. 2001, 108

Trigo-Rodriguez, J.M. et al. 1999, WGN 27, 258

Trigo-Rodriguez, J.M. et al. 1999, WGN 28, 31

Trigo-Rodriguez, J.M., Fabregat, J., \& Llorca, J. 2001a, Meteorit. Planet. Sci., 36, 1597

Trigo-Rodriguez, J.M., Fabregat, J., Llorca, J., et al. 2001b, WGN, 29, 139

Uchiyama, S.2002, WGN, 30, 47

Ueda, M. et al. 2001, SP-495, 325

Ueda, M., Maegawa, K. 2001, SP-495, 413

Watanabe, J., Takahashi, Y., Sasaki, A., et al. 2000, PASJ, 52, L21

Watanabe, J., Sekiguchi, T., Shikura, M., et al. 2002, PASJ, 54, L23

Webster A.R, Jones J., and Ellis K.J. et al. 2001, SP-495, 39

Wickramasinghe, N. C., \& Hoyle, F. 2001, Astrophys. Space Sci. 277, 625

Wilson, J.K., Smith, S., Baumgardner, J., et al. M. 1999, Geophys. Res. Lett., 26, 1645

Wright, I.P. 2001, Adv. Space Res., 28, 1341

Wu, G.J. 1999, CA\&A (Letters), 23, 268

Wu, G.J. 2001, Acta Astronomica Sinica, 42, 125

Wu, G.J., \& Zhang, Z.S. 2000, Earth, Moon \& Planets, 81, 193

Wu, G.-J., Li, G.-Y., \& Ma, Y.-H. 2001, SP-495, 141

Wu G. J., \& Zhang Z. S., 2002, PSS 50, 379

Yanagisawa, M. \&Narumi, K. 2002, Icarus, 159, 31

von Zahn, U. et al. 1999, Meteorit. Planet. Sci., 34, 1017

von Zahn, U. 2001, SP-495, 303

von Zahn U., von der Gathen P., \& Hansen G., 1987, GRL 14, 76

Zender, J., Koschny, D., \& Neira, L. 2000, Earth Moon Planets, 82-83, 39

Zinn, J., Wren, J., Whitaker, R. et al. 1999, Meteoritics Planet. Sci. 34, 1007

Zubareva, E.N., Stulov, V.P. \&, Stulov, P.V. 1999, Solar Syst. Res. 33, 316 